\title{
Cost-effective telecom/datacom semiconductor lasers
}

Nong Chen, Dick T. R. Chen, Wei Hsin, Steven Bo Chen, Frank Xiong, et al.

Nong Chen, Dick T. R. Chen, Wei Hsin, Steven Bo Chen, Frank Xiong, Hernan Erlig, Paul Chen, Xian-li Yeh, David C. Scott, Axel Sherer, "Costeffective telecom/datacom semiconductor lasers," Proc. SPIE 6782,

Optoelectronic Materials and Devices II, 67821J (12 December 2007); doi: $10.1117 / 12.754558$

SPIE. Event: Asia-Pacific Optical Communications, 2007, Wuhan, China 


\title{
Cost-effective telecom/datacom semiconductor lasers
}

\author{
Nong Chen*a, Dick T. R. Chen ${ }^{\mathrm{a}}$, Wei Hsin', Steven Bo Chen ${ }^{\mathrm{a}}$, Frank Xiong ${ }^{\mathrm{a}}$, \\ Hernan Erlig**a, Paul Chen ${ }^{\mathrm{a}}$, Xian-li Yeh ${ }^{\mathrm{a}}$, David C. Scottt ${ }^{\mathrm{a}}$, Axel Sherer ${ }^{\mathrm{b}}$ \\ ${ }^{a}$ Archcom Technology, Inc., 1335 W. Foothill Blvd., Azusa, CA 91702, USA \\ ${ }^{\mathrm{b}}$ California Institute of Technology, Pasadena, CA 91125, USA
}

\begin{abstract}
The recent development of semiconductor laser technologies for cost-effective telecom/datacom applications is reviewed in details in this paper. This includes the laser design, laser chip technology, laser packaging technology and other low cost lasers (chip + packaging). Some design and simulation examples in Archcom laser production are described first. A latest trend in the wafer scale testing/characterization/screening technology for low cost semiconductor laser mass production is discussed then. An advanced long wavelength high power single mode surface emitting laser with wafer scale characterization using our unique mask free focused ion beam (FIB) etching technology is also demonstrated. Detailed descriptions on our wide temperature range $\left(-50{ }^{\circ} \mathrm{C}\right.$ to $\left.+105{ }^{\circ} \mathrm{C}\right)$ G-PON distributed feedback (DFB) semiconductor lasers with high performance and low cost wafer design are included. Cost reduction innovations in laser package with our beam profile improved laser and optical feedback insensitive (OFBI) laser are also addressed.
\end{abstract}

Keywords: Cost effective, wafer-scale testing, surface emitting, mask free, un-cooled laser, tunable laser, integrated laser, surface mount, mode converted laser, isolation-free laser

\section{INTRODUCTION}

Cost effective telecom/datacom semiconductor lasers are becoming more and more important today with the increasing network traffic and decreasing profit margin. Both the carriers and component suppliers are seeking low cost solutions by developing new technologies and reducing manufacturing cost. The low cost requirement doesn't compromise on any performance yield. Actually the performance requirement to the semiconductor laser components today is much higher and tighter than before. It is very challenging to reduce the laser manufacturing cost while keeping even higher laser performances. In long term, technology development is more important than just relocating the manufacturing site to cost inexpensive countries. This invited paper will briefly review the recent technologies or trends of semiconductor lasers for cost-effective telecom/datacom applications and present some of low cost and high performance laser devices developed by the author team in detail.

This article will be divided into the following four sections for detailed discussions: laser design and simulation, laser chip technology, laser packaging technology and other low cost lasers (chip + packaging).

\section{DESIGN AND SIMULATION}

A right and good laser design determine the high performance and low cost of a semiconductor laser. Some one can even think of a low cost device business by choosing fab-less model with a successful device design only. Of course this is cost sensitive to the manufacturing partners, but could be one of the future options for semiconductor laser start up. Actually the fab-less option is popular in silicon industry and some compound semiconductor laser companies have been trying this business model by using standard world-class foundries in both laser chip and packaging. Some companies with design center in the labor expensive countries may also have manufacturing base in labor inexpensive countries.

*nchen@archcomtech.com; phone: 1626969 0681, ext. 234; fax: 1626969 7699; http://www.archcomtech.com

**Hernan Erlig is now with JPL. This work was done when he was with Archcom Technology, Inc. 


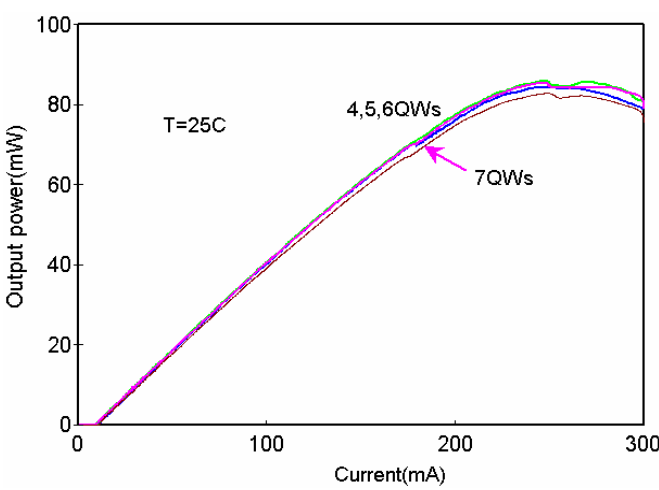

(A) Room temperature L - I data

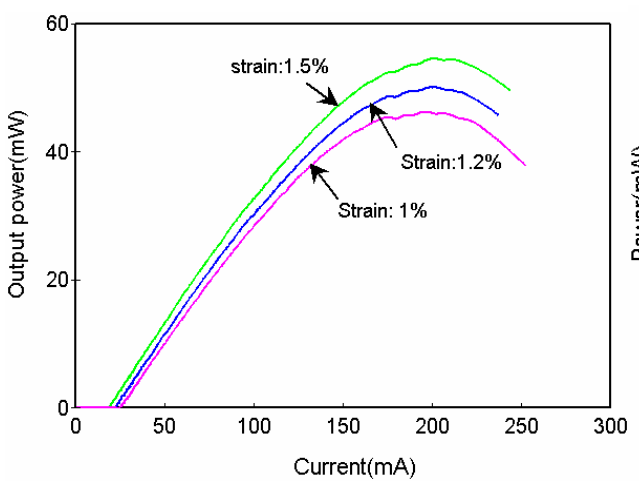

(C) High temperature $\left(70^{\circ} \mathrm{C}\right) \mathrm{L}-\mathrm{I}$ data

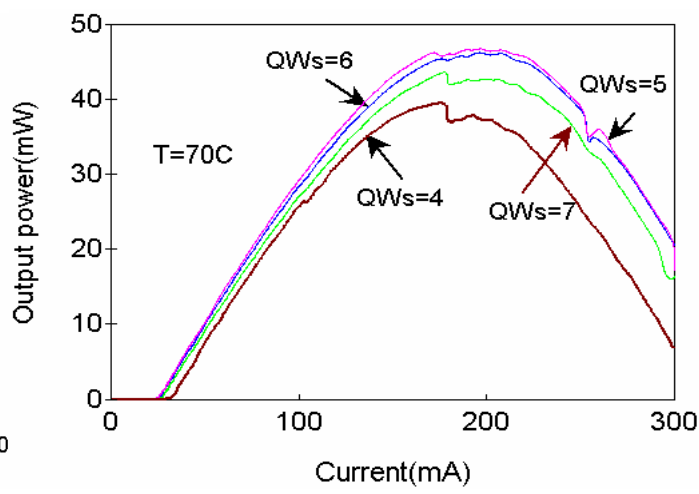

(B) High temperature $\left(70^{\circ} \mathrm{C}\right) \mathrm{L}-\mathrm{I}$ data

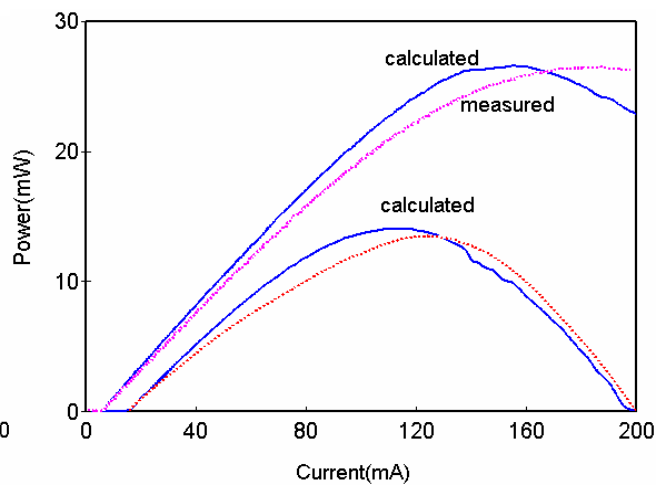

(D) Comparison of simulated and fabricated lasers

Fig. 1 Some simulated examples in our $1550 \mathrm{~nm} \mathrm{BH}$ laser design for optimizing the quantum well (QW) active layer structure (A) L - I curve at room temperature with different QW number. (B) The L - I curve at high temperature $\left(70{ }^{\circ} \mathrm{C}\right)$ with different QW number. $(\mathrm{C})$ The L - I curve at high temperature $\left(70{ }^{\circ} \mathrm{C}\right)$ with different QW strain. (D) Example of a $440 \mu \mathrm{m}$ long cavity laser with two facets as cleaved BH FP laser at room temperature $25^{\circ} \mathrm{C}$ and high temperature $70{ }^{\circ} \mathrm{C}$ for comparison of simulated and fabricated lasers. This analysis helps to design our high power laser at high temperature for un-cooled low cost package.

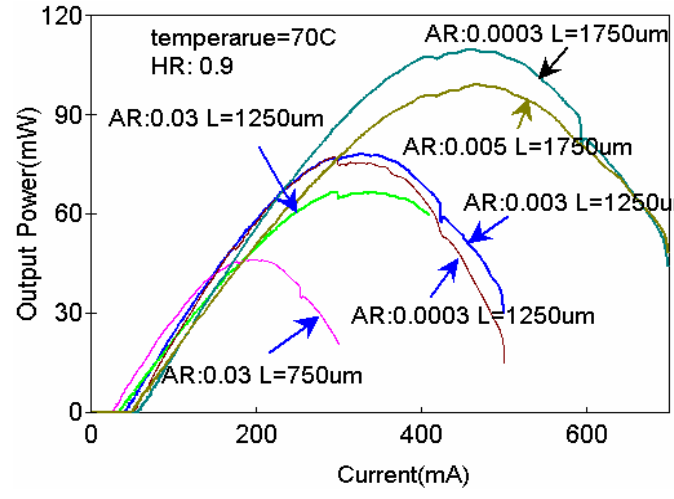

(A) Laser cavity optimization design

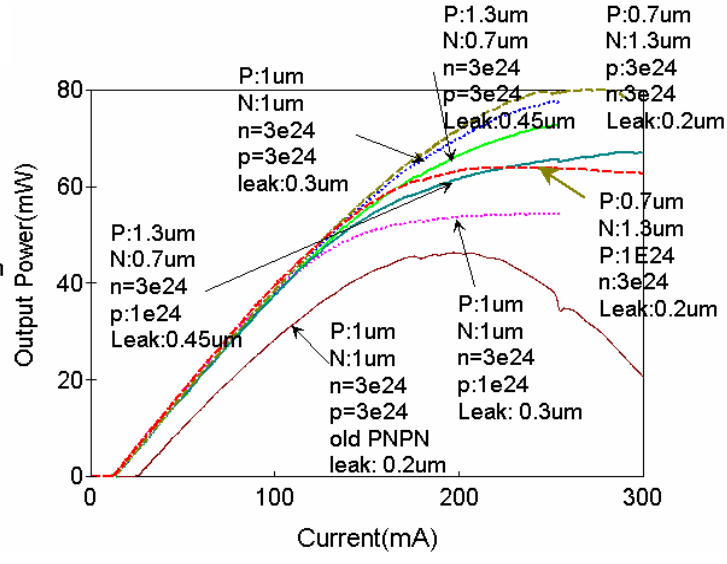

(B) $\mathrm{BH}$ laser blocking layer optimization design

Fig. 2 Simulated examples in our $1550 \mathrm{~nm} \mathrm{BH}$ laser design for optimizing (A) the laser cavity and facet mirror structure, (B) the blocking layer structure in our BH lasers with different $\mathrm{P}$ and $\mathrm{N}$ type layer thickness and doping level (unit: $\mathrm{m}^{-3}$ ). The leak value is the leakage channel width between the laser active layer and the $\mathrm{N}$ type blocking layer in lateral dimension (so called PPN leakage). A high performance design results in a low cost for our wafer fabrication because of the tolerant yield. 
For example in our case, by only optimizing the wafer structure design and grating structure design, we have manufactured and achieved very wide temperature $\left(155^{\circ} \mathrm{C}\right.$ temperature range) high performance DFB lasers for cost effective optical communication networks such as fiber to the home (FTTH) application with matured semiconductor material and matured semiconductor process technology, instead using special material and process which usually cause additional expense in mass production. This laser device performance will be addressed in another section later.

Semiconductor laser design and simulation technologies have been well developed by researchers and commercialized by design software companies ${ }^{1-9}$. We have also used the simulator to design our high power laser at high temperature for un-cooled low cost package. Fig. 1 shows some examples of our simulated $1550 \mathrm{~nm}$ BH laser output power data for optimizing our laser active layer strained quantum well (QW) structure design. Our fabricated laser result is very close to the simulated data when the similar parameters are used. The fabricated device performance will be described later in other section. Fig. 2 exhibits more examples of our $1550 \mathrm{~nm} \mathrm{BH}$ lasers on (A) the laser cavity and mirror structure optimization design, (B) the blocking layer thickness and doping level optimization design. The leak value in the figure is the leakage channel width between the laser active layer and the $\mathrm{N}$ type blocking layer in lateral dimension (so called PPN leakage). A high performance design results in a low cost for our wafer fabrication because of the tolerant yield.

In the semiconductor laser design, since too many device parameters may affect the laser performance, a design of engineering (DOE) or Taguchi method is usually helpful to get to the right design efficiently. ${ }^{2}$

\section{LASER CHIP TECHNOLOGY}

\subsection{Laser wafer epitaxial growth}

The most of laser chip cost is from epitaxial growth such as metal organic chemical vapor deposition (MOCVD) which is a popular mass production tool, but the equipment, sources, and maintenance are very costly. One solution is to use commercially available laser epi wafer. This is good for some general or standard laser structures and some custom made laser structures. Usually Fabry Perot (FP) lasers are using this option. Standard DFB lasers may be difficult to use outsourcing epi wafer because grating fabrication and re-growth are critical processes. This had motivated the research and development of some special type DFB lasers with re-growth free technology, such as surface grating DFB lasers ${ }^{10-12}$ and laterally coupled (LC) DFB ridge lasers ${ }^{13-15}$.

\subsection{RW laser vs. BH laser}

Ridge wave guide (RW) laser is the lower cost type of the most popular edge emitting semiconductor lasers compared to the BH type. It is easier to fabricate with higher process yield for RW laser production. However one may have to compromise on the laser performance such as higher threshold, lower optical power, poorer high temperature performance, non-circular beam profile (for example $25^{\circ} \times 40^{\circ}$ vs. $30^{\circ} \times 35^{\circ}$ for $\mathrm{RW}$ vs. $\mathrm{BH}$ ). A higher laser threshold often leads to the laser in higher cost because it needs cooler for high temperature applications. One of the solutions is to make the ridge laser better performance and maintain the similar cost in wafer fabrication process. Reversed mesa ridge laser ${ }^{16-18}$, laterally oxidized ridge laser including quantum dot laser ${ }^{19-22}$, the ridge laser with laterally undercut etched current confinement structure ${ }^{23-24}$ and other structures ${ }^{25-26}$ are some typical examples.

\subsection{InGaAsP laser vs. InGaAlAs laser}

A better laser base material system is also a key factor in cost sensitive semiconductor lasers. For $1.3 \mu \mathrm{m}$ and $1.5 \mu \mathrm{m}$ wavelength semiconductor lasers used in the cost effective telecom and datacom networks, InGaAsP/InP is the conventional and most matured base material system. Wafer fabrication process has been well developed and yield is high in InGaAsP/InP lasers ${ }^{25-31}$ mass production. Usually BH structure is needed for high temperature performance for this material system per the description above. A solution from the view of base material system is to use larger band gap off-set material for better carrier confinement to achieve better performance in high temperature. InGaAlAs/InP lasers ${ }^{32-35}$ and GaInNAs/GaAs lasers ${ }^{36-40}$ are typical examples, in which InGaAlAs/InP laser is leading the trend while GaInNAs/GaAs laser does not work out so far for mass production.

\subsection{Edge emitting laser vs. surface emitting laser}

Edge emitting laser is still dominant in the market especially for long wavelength laser sources. Vertical cavity surfacing emitting laser (VCSEL) ${ }^{41-48}$ has been well developed especially with GaAs based material in short wavelength market. 
Compared to the edge emitting type semiconductor lasers, surface emitting semiconductor lasers, including VCSEL and horizontal cavity surface emitting lasers (HCSEL) ${ }^{49-51}$, are more cost effective due to less labor involvement in laser bar testing, bar coating in laser wafer manufacturing. In addition, we have developed focusing ion beam etched surface emitting laser (FIBESEL) ${ }^{52-53}$ with unique process flexibility and complete mask free technologies. This additional convenience makes post device process also possible. For example, a process-completed and chip-mounted but not sealed FP laser can still be easily processed into a single mode laser with cavity structure post-changed by the FIBE process ${ }^{52}$.

Table 1 lists the process comparison for edge emitting and surface emitting lasers, including VCSEL, HCSEL and FIBESEL in manufacturing flow. It is clearly shown the process step reduction in surface emitting laser manufacturing process. Especially the bar cleaving and bar fixture for facet anti-reflection (AR) coating and high reflection (HR) coating are very much labor intensive because so many bars generated from a wafer and the fixture for AR and HR coating is critical. The facet coating fixture also wastes several laser devices for each laser bar because it clamps each end of the laser bars. All these can be avoided in surface emitting laser manufacturing because of the wafer scale process and wafer scale auto testing. Of course, for R\&D sampling, there is no significant difference in the cost, but in mass production, the cost is very different. The cost saving rank is also listed in the table for reference.

Table 1 Comparison of edge emitting and surface emitting lasers in manufacturing process. It is shown that edge emitting laser has 9 steps, VCSEL has 5 steps, HCSEL has 7 steps, FIBESEL has 6 steps in total.

\begin{tabular}{|c|c|c|c|c|}
\hline Process Steps & Edge Emitting Laser & VCSEL & HCSEL & FIBESEL \\
\hline Epi-growth (standard laser) & 1 & 1 & 1 & 1 \\
\hline Epi-growth (laser mirrors) & & 2 & & \\
\hline Wafer process & 2 & 3 & 2 & 2 \\
\hline Laser cavity/mirrors lithography & & & 3 & \\
\hline Laser cavity/mirrors etching & & & 4 & 3 \\
\hline Laser cavity/mirrors coatings & & & 5 & 4 \\
\hline Wafer Scale testing (auto test) & & 4 & 6 & 5 \\
\hline Wafer cleaving into laser chips & & 5 & 7 & 6 \\
\hline Wafer cleaving into laser bars & 3 & & & \\
\hline Initial laser bar testing & 4 & & & \\
\hline Laser bar loading into fixture & 5 & & & \\
\hline Laser bar front facets coating & 6 & & & \\
\hline Laser bar rear facet coating & 7 & & & \\
\hline Laser bar testing and screening & 8 & & & \\
\hline Laser bar cleaving into chips & 9 & & & \\
\hline Process cost saving rank & $\mathrm{D}$ & A & $\mathrm{C}$ & $\mathrm{B}$ \\
\hline Remarks & High power & Low power & \multicolumn{2}{|c|}{ High power available } \\
\hline & Wide temperature & Short $\lambda$ & \multicolumn{2}{|c|}{ Wide temperature range } \\
\hline & Much more laboring & & & Flexible \\
\hline & from 3 to 9 steps & & & Mask free \\
\hline & Rank D: higher cost & & & \\
\hline
\end{tabular}

VCSEL is very good in applications like some datacom networks requiring less optical power. Using advanced focusing ion beam (FIB) technology, we have developed surface emitting long wavelength DFB laser with high power and wide temperature range. This is not achievable yet with the existing VCSEL technology. Compared to HCSEL, FIBESEL is more flexible and accurate in process of a nanometer scale. In addition, it needs no mask and lithography. A production model of the FIB machine is also very fast in speed and high in throughput.

Figure 3 shows a schematic drawing of our FIB etched surface emitting DFB laser in a side view. It is noted that the FIB etched mirror process is complete mask free and the FIB etched mirror location is accurate and flexible. This means we 
can even make the laser mirrors or new cavities after the device process is all completed based on the requirements of applications, especially for some special and unique applications.

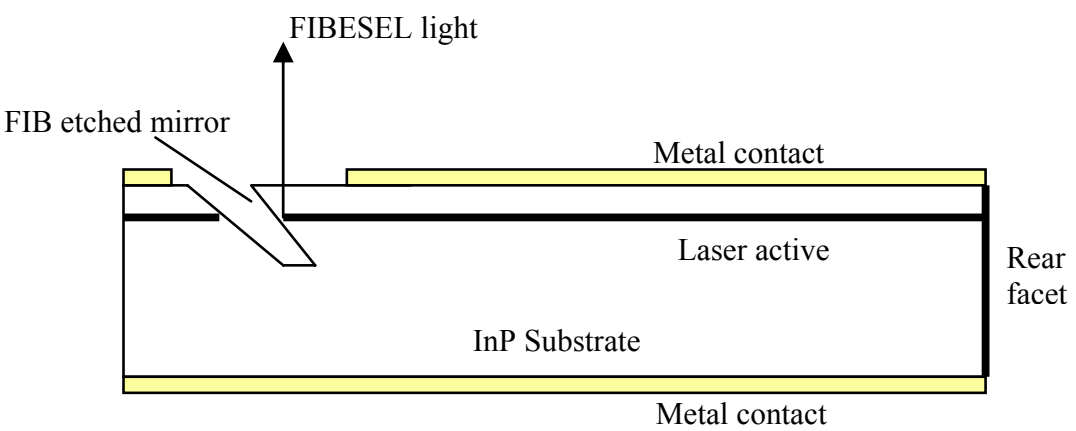

Fig. 3 A side view of the illustrated $1.5 \mu \mathrm{m}$ wavelength DFB FIBESEL device fabricated with our unique mask free etching technology for high power and wide temperature cost effective telecom and datacom applications.

Figure 4 is a scan electron microscope (SEM) picture showing the DFB laser with (A) RW structure (B) BH structure. FIB etching process is also flexible to material and the shape of the surface. It can directly cut through the metal, dielectric film and semiconductor material. We opened an area with metal lift off on the laser wafer chip surface for light emitting window, not for process. The FIB etched mirror surface is very smooth, but the opposite side of the etched surface may have some roughness because of the re-deposition of the iron source. This can be improved by a cleaning process if both two etched facets are used as mirrors.

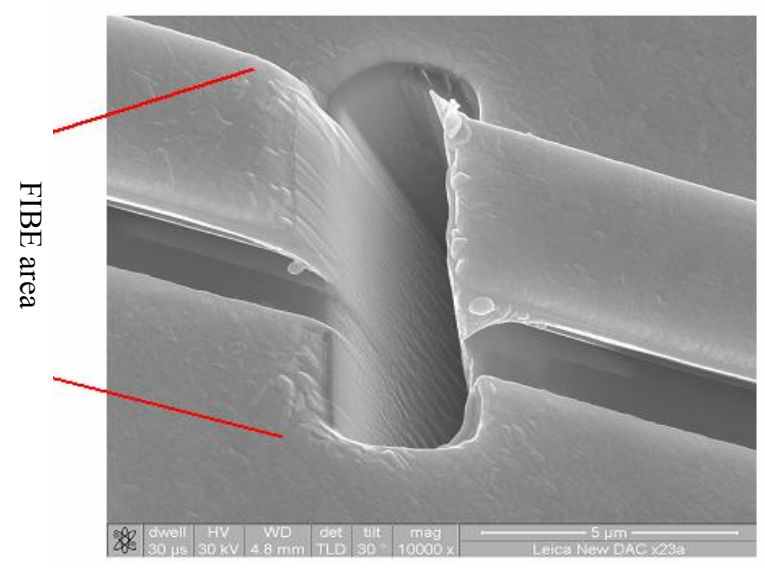

(A) RW DFB FIBESEL chip surface

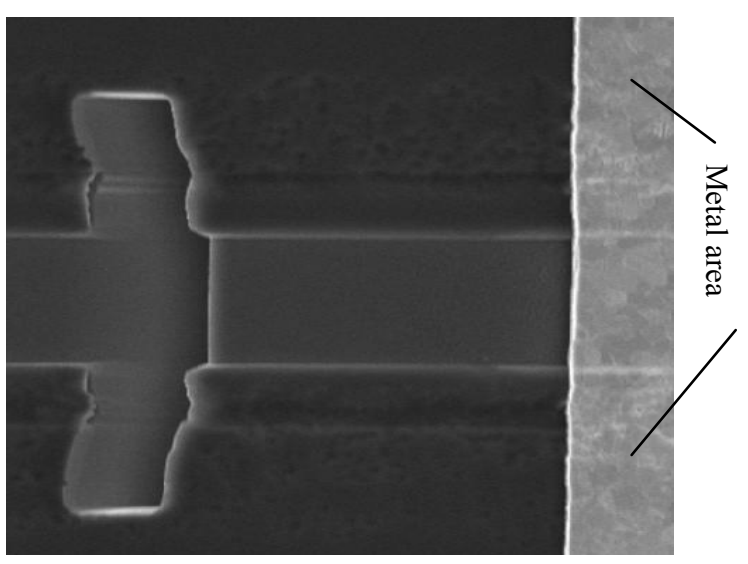

(B) BH DFB FIBESEL chip surface

Fig. 4 A scan electron microscope (SEM) showing our $1.5 \mu \mathrm{m}$ wavelength DFB FIBESEL chip surface with $(\mathrm{A})$ ridge wave guide $(\mathrm{RW})$ structure, $(\mathrm{B})$ buried hetero $(\mathrm{BH})$ structure

Figure 5 gives the output power and spectrum data example of our fabricated DFB FIBE laser device under different temperatures. Avery good single mode stability with the side mode suppression ratio (SMSR) above $40 \mathrm{~dB}$ was maintained in a wide temperature range. Fig. 6 demonstrates a group of the $10,000 \mathrm{hrs}$ life test data at $100{ }^{\circ} \mathrm{C}, 200 \mathrm{~mA}$ for our fabricated DFB FIBESEL devices. There is no degradation observed so far, which shows the high reliability of the FIB processed DFB laser. The life testing is still continuing. 

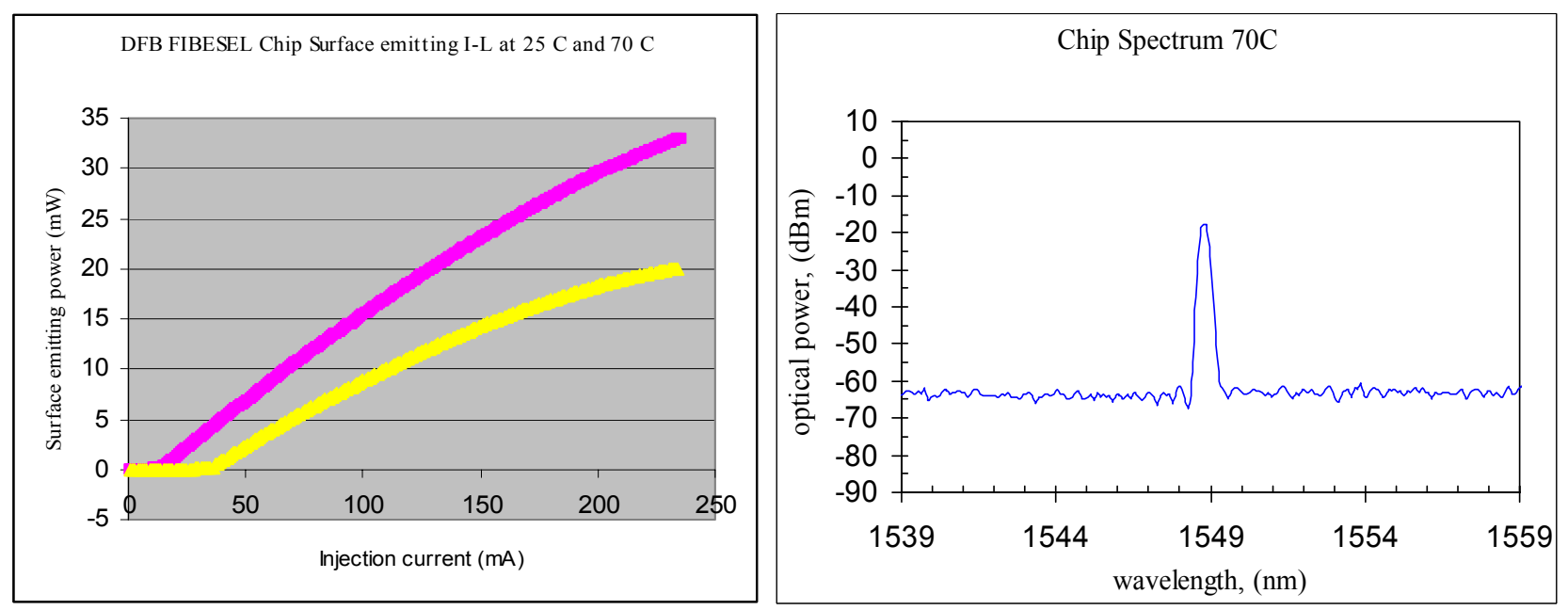

Fig. 5 One example of the measured data from our $1.5 \mu \mathrm{m}$ wavelength DFB FIBESEL laser chip surface emitting power and spectrum at $25{ }^{\circ} \mathrm{C}$ and $70{ }^{\circ} \mathrm{C}$ with a good single mode stability (side mode suppression ratio all above $40 \mathrm{~dB}$ at both room temperature and high temperature)

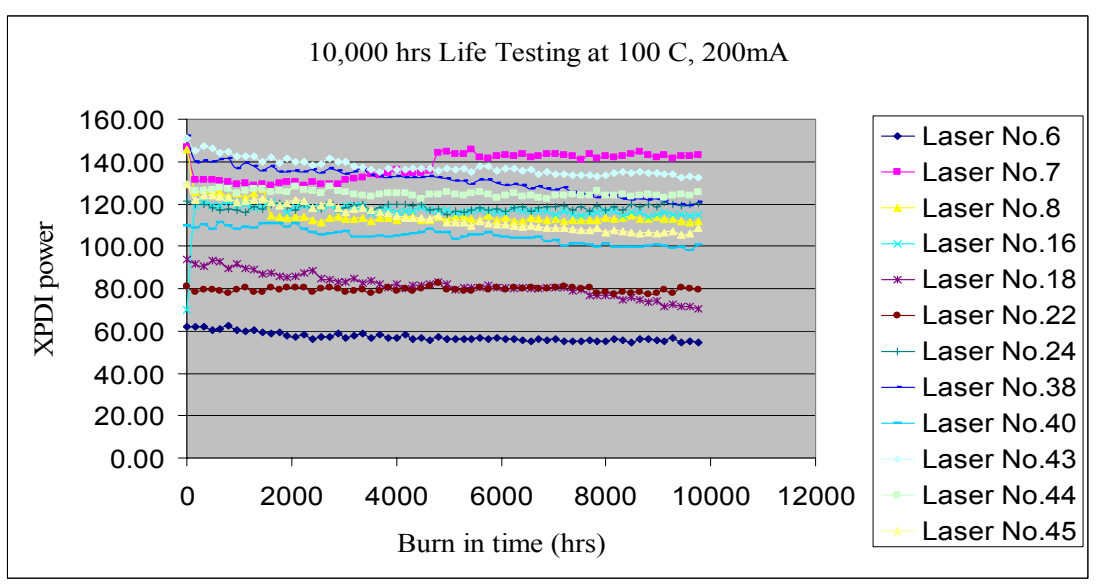

Fig. 6 10,000 hrs life time testing data at $100{ }^{\circ} \mathrm{C}, 200 \mathrm{~mA}$ of our DFB FIBESEL device

\section{LASER PACKAGING TECHNOLOGY}

The semiconductor laser chip is only a part of the laser module. Assembling the laser module is also a key technology in mass production. The packaging cost reduction may be done by parts elimination, alignment simplification, assembling automation, and the related key technology improvement. The advances in the electrical, mechanical, and optical design and materials of laser packages have resulted in performance improvements and cost reductions.

For example, the DFB laser and pump laser butterfly package are gradually reforming to mini-DiL, mini-butterfly, coaxial package. TO and TOSA/ROSA are also getting simpler in design. Fig. 7 shows some examples of Archcom semiconductor laser packages with the cost effective solution.

Recently a plastic package is used to replace some of the metal packages for further cost reduction. This represents the material solution for the low cost packaging. Others like flip chip bonding and passive alignment are also becoming common approaches. The hermitic package towards non-hermitic package is another example of the cost reduction. 


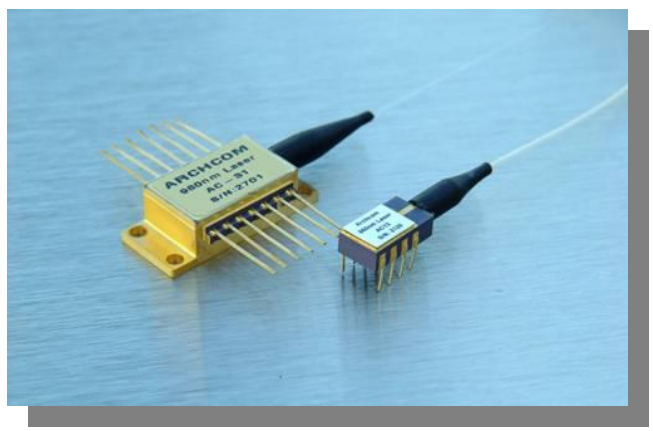

(A) Cooled and un-cooled mini-DiL butterfly

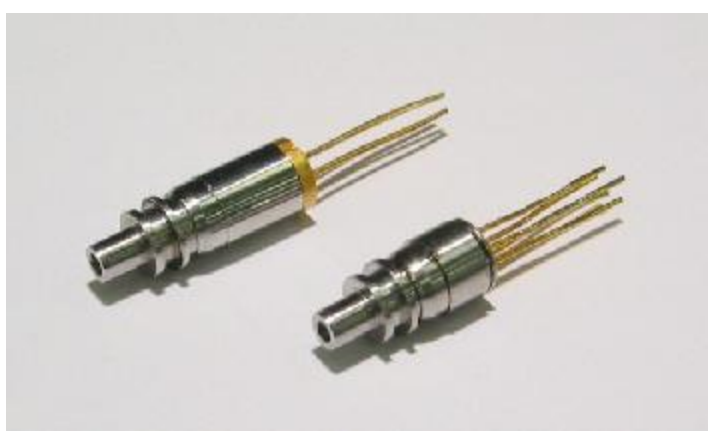

(B) Un-cooled DFB TOSA and APD-TIA ROSA pair

Fig. 7 Pictures of some laser packages with (A) cooled and un-cooled Mini-DiL butterfly laser package (B) un-cooled DFB TOSA and APD-TIA ROSA pair for low cost applications.

\section{OTHER LOW COST LASERS - (CHIP + PACKAGING)}

\subsection{Un-cooled laser chip and coaxial packaging}

The elimination of thermal electric cooling (TEC) from coaxial package that requires the laser chip with better performance in high temperature. This increases the laser chip cost, but significantly decreases the laser packaging size and cost. It results in a final system cost down. This technology is not only for FP laser, now also extends to un-cooled DFB laser, un-cooled course wavelength division multiplexing (CWDM) laser, un-cooled electro-absorption modulated laser (EML), and so on.

Un-cooled semiconductor lasers are recently well developed for wide temperature applications ${ }^{54}$. Typical un-cooled semiconductor lasers have been mainly developed by using $\mathrm{Al}$ included material for its better temperature characteristics, as discussed in section 3.3 in this paper. We also developed an extremely wide temperature DFB laser for the cost sensitive fiber to the home (FTTH) giga bit rate passive optical network (GPON) applications. Due to easy oxidization of Al included material, re-growth process is not preferred for this material system if manufacturing cost is sensitive. Usually high performance FP lasers and standard DFB lasers all require re-growth. This makes the Al included laser a little bit high cost than the most popular laser material. With optimized wafer design, we have used the most popular and matured InP material, which has much higher wafer process yield than the Al included material especially in $\mathrm{BH}$ structure lasers, to fabricate un-cooled DFB lasers with ultra wide temperature range.

The typical test data of our fabricated $1310 \mathrm{~nm}$ wavelength DFB lasers resulted in the laser threshold around $7 \mathrm{~mA}$ at room temperature, $4 \mathrm{~mA}$ at lower temperature $\left(-40^{\circ} \mathrm{C}\right)$, and $22 \mathrm{~mA}$ at high temperature $\left(85^{\circ} \mathrm{C}\right)$. The laser was measured with standard transmitter optical subassembly (TOSA) package. The laser output power all exceeded $4 \mathrm{~mW}$ in an ultra wide temperature range, and meet the requirement of FTTH system.

This laser maintains very good single mode stability in an ultra wide temperature range. Fig. 8 shows the spectrum at (A) extremely low temperature $\left(-50{ }^{\circ} \mathrm{C}\right)$, (B) low temperature $\left(-40^{\circ} \mathrm{C}\right),(\mathrm{C})$ room temperature, and (D) high temperature of $105^{\circ} \mathrm{C}$. The side mode suppression ratio (SMSR) is above $40 \mathrm{~dB}$ at $-50{ }^{\circ} \mathrm{C}$ and $-40{ }^{\circ} \mathrm{C}, 48 \mathrm{~dB}$ at $25{ }^{\circ} \mathrm{C}, 42 \mathrm{~dB}$ at $105^{\circ} \mathrm{C}$. It has much more temperature margin to the FTTH requirement with ultra wide temperature range of $180^{\circ} \mathrm{C}$.

The above un-cooled 1310 DFB laser is very suitable for the low cost FTTH application including giga bit rate passive optical network (GPON) system optical network unit (ONU) that requires wide temperature range (usually from $-40{ }^{\circ} \mathrm{C}$ to $85{ }^{\circ} \mathrm{C}$ ) and single mode. The same un-cooled laser technology has also been applied to our $1490 \mathrm{~nm}$ DFB laser for FTTH GPON optical line terminal (OLT) and other $1310 \mathrm{~nm}$ and $1550 \mathrm{~nm}$ DFB laser applications such as course wavelength division multiplexing (CWDM) networks uses. Fig. 9 is an example of our extended temperature $1550 \mathrm{~nm}$ DFB laser for low cost application. Fig. 10 shows our CWDM DFB laser for both metro broad band and LX4 applications. 


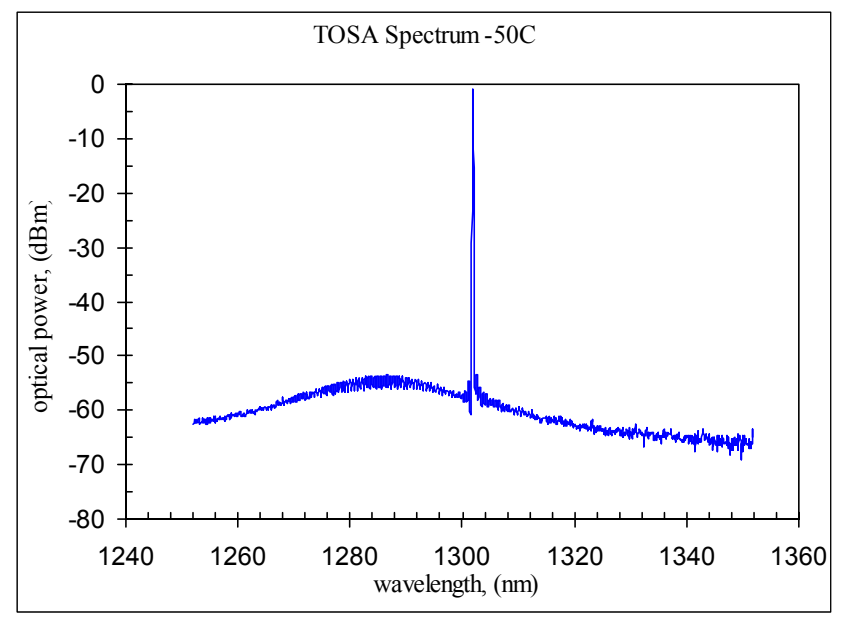

(A) Spectrum at lower temperature of $-50{ }^{\circ} \mathrm{C}$

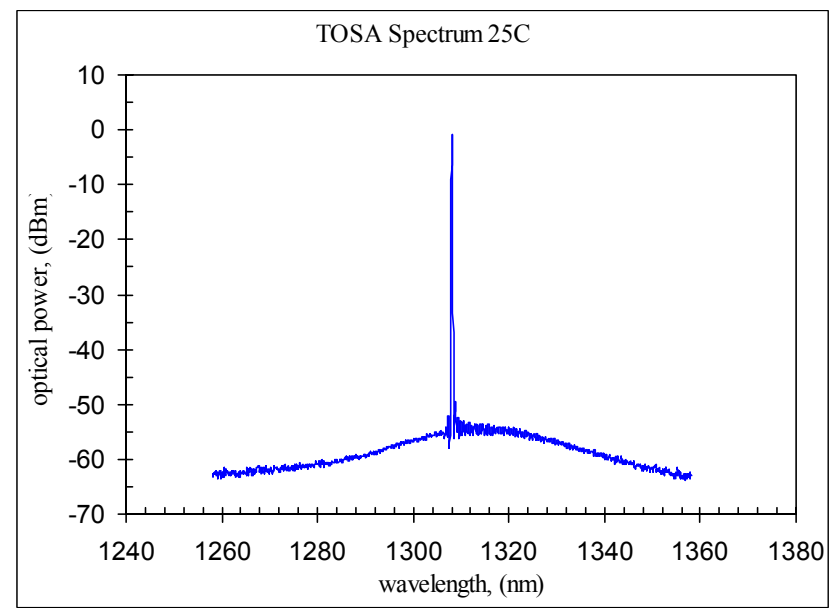

(C) Spectrum at room temperature of $25^{\circ} \mathrm{C}$

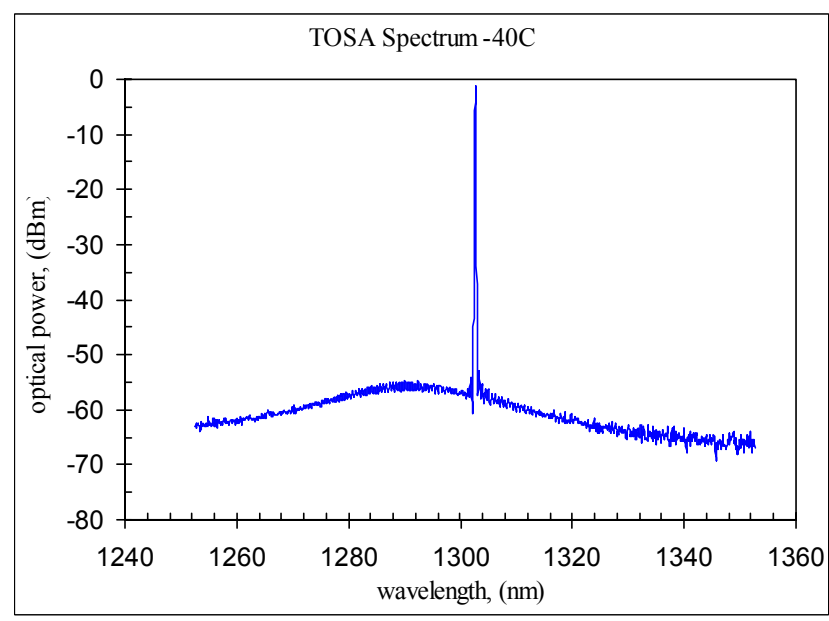

(B) Spectrum at low temperature of $-40{ }^{\circ} \mathrm{C}$

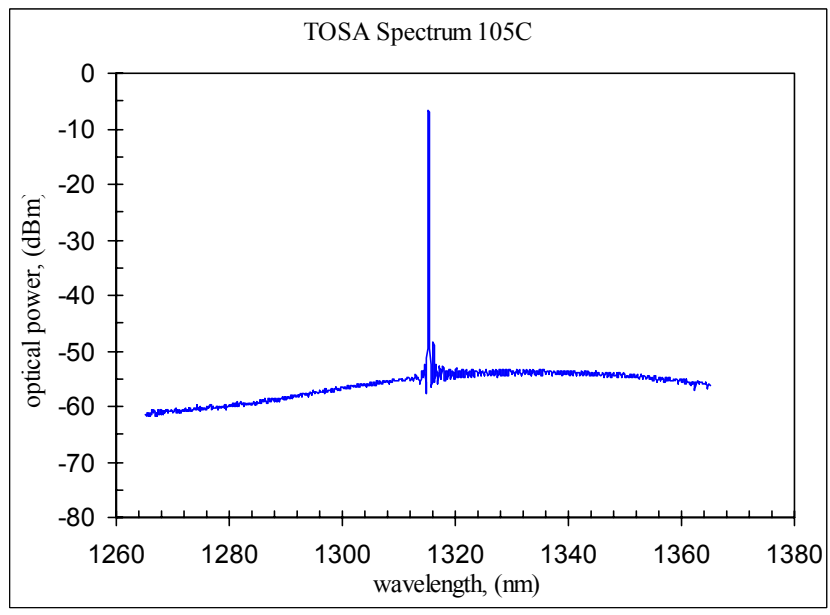

(D) Spectrum at high temperature of $105^{\circ} \mathrm{C}$

Fig. 8 Typical spectrum examples of our fabricated $1310 \mathrm{~nm}$ DFB laser under different temperatures. (A) was measured at $-50{ }^{\circ} \mathrm{C}$, (B) was measured at $-40{ }^{\circ} \mathrm{C}$, (C) was at room temperature and (D) was at $105^{\circ} \mathrm{C}$. They all demonstrated a very stable single mode with high enough side mode suppression ratio in a very wide temperate range of $155^{\circ} \mathrm{C}$. This created tremendous temperature margin for practical un-cooled wide temperature uses.

\subsection{Tunable laser}

Functional laser devices like the tunable lasers ${ }^{55-63}$ including continuously wavelength tunable laser for fine tuning application ${ }^{4,64-65}$ are still somewhat high cost in each individual device, but they significantly reduce the inventory cost for systems especially in wavelength division multiplexing (WDM) networks, in addition to their added values in many other applications like measuring and sensing systems. As the technology advancing today, it will be expectable that every semiconductor laser is multi-functional in the future. This may reduce the number of needed components in the networks. 


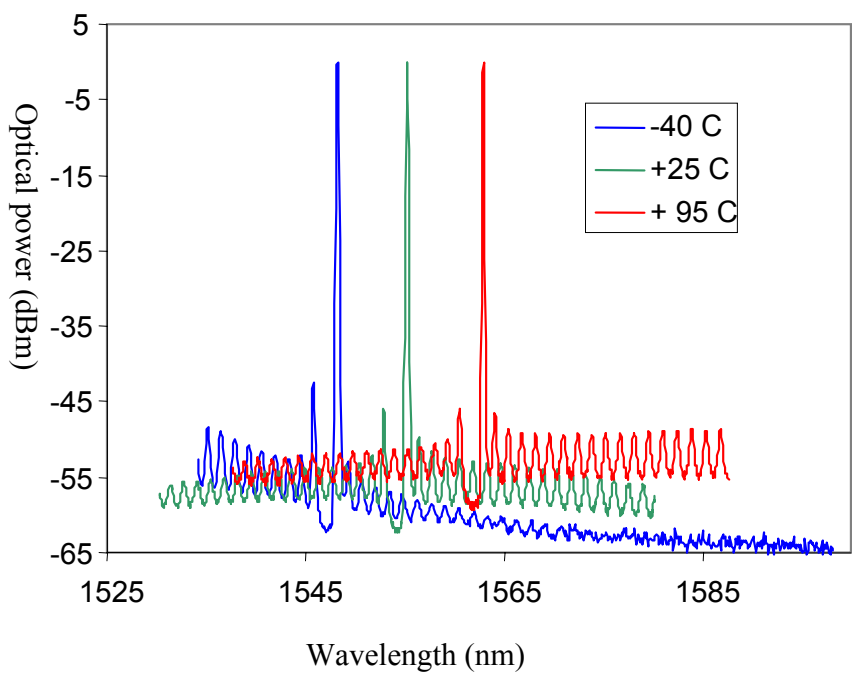

Fig. 9 An example of our extended temperature $1550 \mathrm{~nm}$ DFB laser for low cost application.

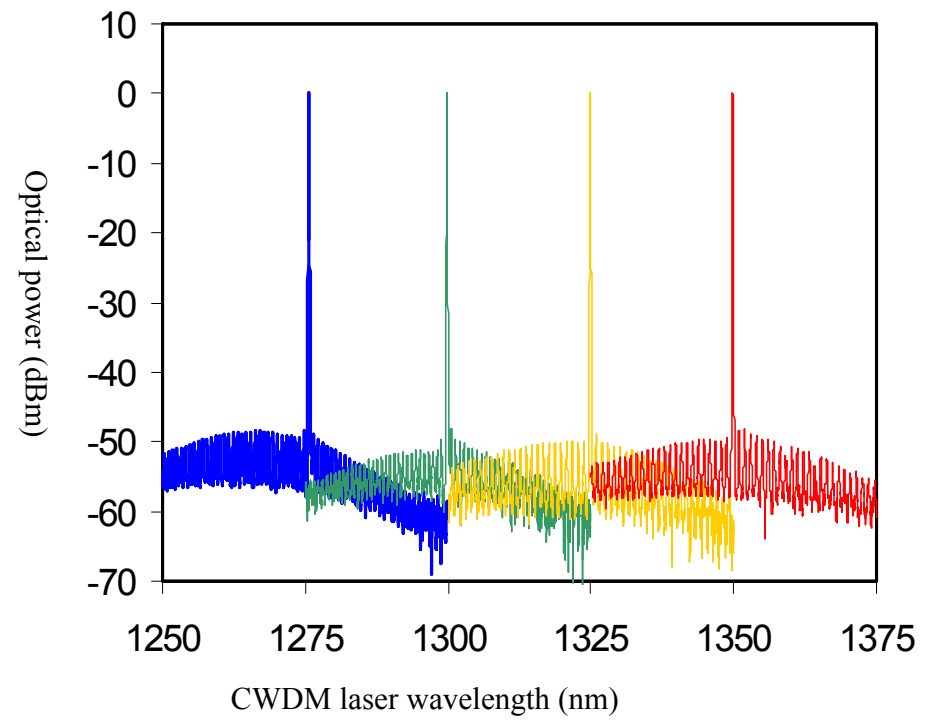

Fig. 10 An example of our CWDM DFB laser for both metro broad band and LX4 applications.

\subsection{Integrated lasers}

Similar to the above mentioned tunable lasers, the monolithically integrated devices like laser integrated with optical amplifier or other devices, such as modulator, mode converter, beam splitter, optical isolator, arrayed wave guide (AWG) and so on ${ }^{66-71}$, bring many functions in a single monolithically integrated device which greatly reduces the size and cost of the systems or subsystems in optical telecom and datacom applications. 


\subsection{Surface mount laser}

The above mentioned monolithic integrated laser devices may take more time for a full commercialization if larger scale monolithic integration is taken into account due to the yield and total cost balance issue. Sometimes the hybrid integration is more practical, especially in the integration with silicon based systems since the silicon laser is not available yet ${ }^{72}$. In this case the surface mount laser technologies are working attractively for cost effective applications such as eliminating hermitic packaging, merging into silicon integrated circuits ${ }^{73-75}$.

\subsection{Mode converter laser}

Edge emitting semiconductor lasers have an issue of imperfect beam profile because of the lateral and transverse confinement structure. This usually causes extra loss in optical coupling to other components and systems. Aspheric lens used in the laser module packaging is effective for improving the optical coupling efficient, but it is much expensive than the regular ball lens. Semiconductor laser with mode converter structure is a good solution to reduce the cost because of the low loss coupling with the improved beam profile ${ }^{76-79}$.

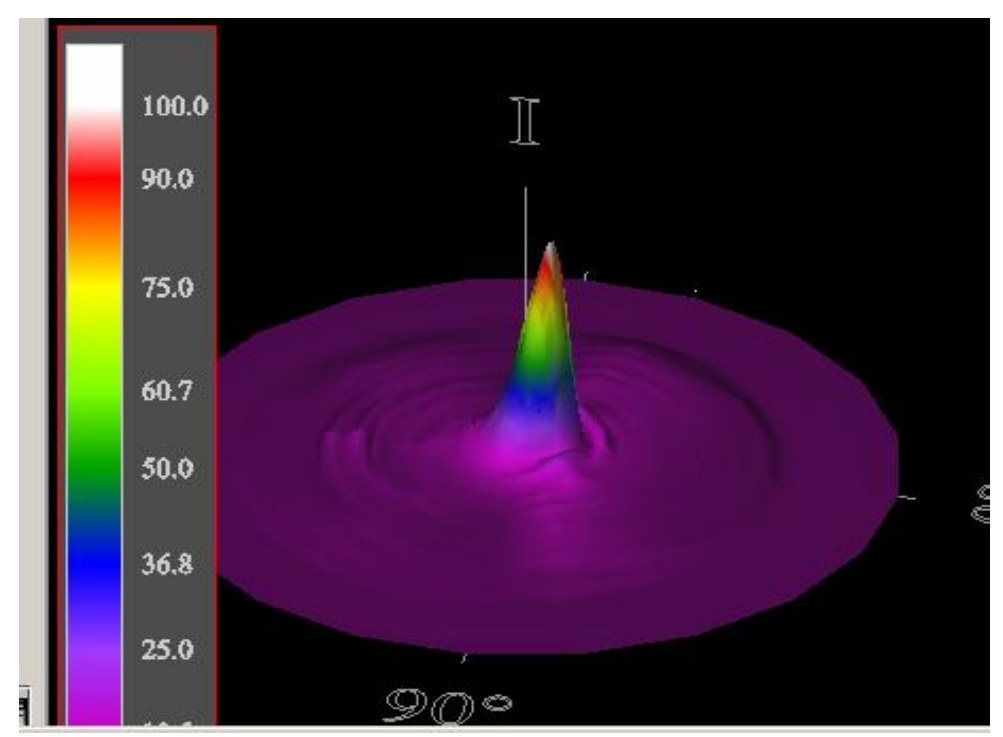

Fig. 11 A far field pattern example of our fabricated SAG laser with the beam angle of $11.5 \times 12$ degree

Figure 11 is a measured far field pattern example of our fabricated selected area growth (SAG) laser. The edge emitting laser beam profile is almost circular in this case. The beam divergence angle is $11.5 \times 12$ degree. This greatly improved the laser beam profile by reducing the far field angles. It is significant in easy and low loss coupling to the fiber or other waveguide systems to result in a total system cost down. A future lens-free, and isolator-free system may become possible with further advancing of this technology.

\subsection{Isolation free laser}

Many semiconductor laser application systems need optical isolator to prevent the light feedback from the system to the laser source for keeping laser device in good lasing performance. To eliminate the isolator is effective in cost consideration since it is expensive to package an isolator in the module for cost sensitive applications. A gain-coupled or complex coupled DFB laser has been investigated for the good resistance to optical feedback ${ }^{80-83}$. Mode converter included or some special designed grating structure lasers have also resistance to the reflection light.

With the simplest optical feedback insensitive (OFBI) technology by using a unique laser design, we have recently demonstrated a reflection resistant DFB laser that can withstand optical reflections with a return loss of only $-7 \mathrm{~dB}$. For many applications, this DFB laser is perfectly suitable to use without an optical isolator which substantially reduces the packaging cost as shown in Fig. 12. 


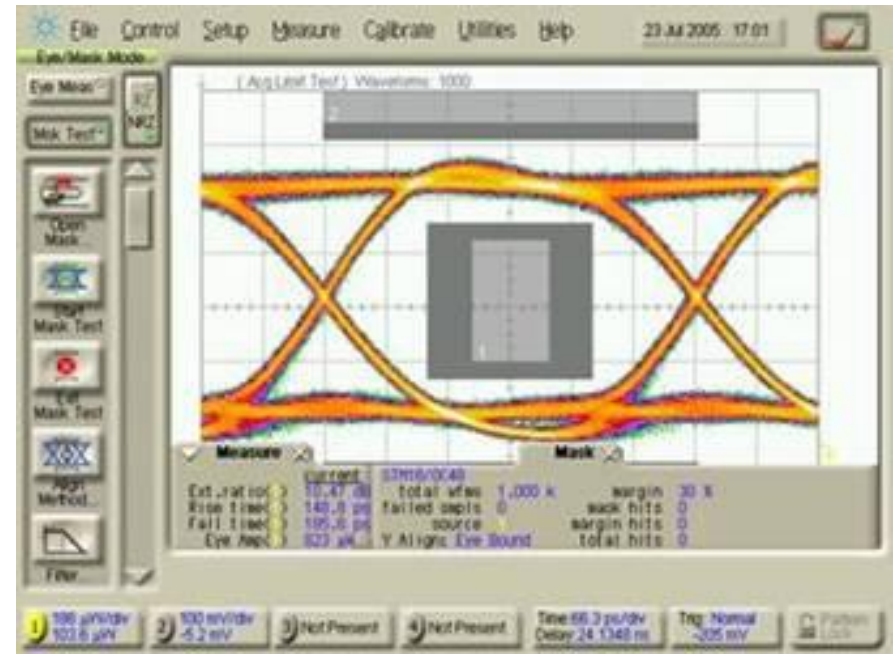

Fig. 12 Eye diagram of our optical feedback insensitive (OFBI) DFB laser with an optical return loss of $-7 \mathrm{~dB}$. No degradation in the eye pattern was observed for an isolator free application.

In addition to the above optical feedback insensitive (OFBI) DFB lasers, another solution may be the monolithic integration of a wave guide type optical isolator and laser ${ }^{84}$. This is higher in cost compared to a single isolation free laser device, but still better than adding a separate isolator component in applications.

\section{REFERENCES}

For example, G. P. Agrawal and N. K. Dutta, Semiconductor lasers, $2^{\text {nd }}$ ed., van Nostrand Reinhold, 1993.

2 J. Darja, S. Narata, N. Chen, and Y. Nakano, "Use of LASTIP in conjunction with orthogonal arrays in optimizing the design of InAlGaAs/InP MQW laser diodes," Proc. of the IEEE/LEOS $3^{\text {rd }}$ NUSOD-03, Tokyo, MC2, 25-26 (2003)

3 N. Chen, S. Narata, J. Darja, Y. Nakano, "Semiconductor lasers designed for cost effective fiber communications," Proc. Of the 8th Sino-Jpn Joint Meeting on Optical Fiber Science and Electromagnetic Theory (OFSET2004), Huangshan, S3-PD1, (2004)

4 N. Chen, Y. Nakano, K. Okamoto, K. Tada, G. Morthier, and R. Baets, "Analysis, fabrication and characterization of tunable DFB lasers with chirped gratings," IEEE J. of Selected Topics in Quantum Electron., 3(2), 541-546 (1997)

5 P. Vankwikelberge, G. Morthier, R. Baets, "CLADISS-a longitudinal multimode model for the analysis of the static, dynamic, and stochastic behavior of diode lasers with distributed feedback," IEEE J. of Quantum Electron., 26(10), 1728-1741 (1990)

6 T. Nakura and Y. Nakano, "LAPAREX-an automatic parameter extraction program for gain- and index-coupled distributed feedback semiconductor lasers and its application to observation of changing coupling coefficients with currents," IEICE Trans. Electron., E83-C(3), 488-495 (2000)

7 B. Grote, E. K. Heller, R. Scarmozzino, J. Hader, J. V. Moloney, and S. W. Koch, "(LaserMOD ${ }^{\mathrm{TM}}$ used in) Chapter 2: Fabry-Perot lasers: Temperature and many-body effects," Optoelectronic Devices - Advanced Simulation and Analysis, J. Piprek (Ed.), Springer, New York, 2005.

8 W. P. Huang, Advanced Laser Diode Simulator (ALDS), http://www.apollophoton.com.

9 M. Jungo, VCSEL Integrated Spatio - Temporal Advanced Simulator (VISTAS), http://vistas.sourceforge.net

10 H. Abe, S. Mitsuya, T. Itoh, M. Sugiyama, S. Sudo, N. Futakuchi, Y. Shimogaki, Y. Nakano, and K. Tada, "1.55 $\mu \mathrm{m}$ surface grating strained MQW DFB laser," Ext. Abstr. $58^{\text {th }}$ Autumn Meet. Jpn. Soc. Applied Phy., 3p-ZC-8, 
$1111(1997)$

11 H. Abe, S. G. Ayling, J. H. Marsh, R. M. De La Rue, J. S. Roberts, " Single-mode operation of a surface grating distributed feedback GaAs-AlGaAs laser with variable-width wave guide," IEEE Photon. Techno. Lett., 7(5), 452454 (1995)

12 M.L. Osowski, R. Panepucci, I. Adesida, J.J. Coleman, "Strained-layer InGaAs-GaAs asymmetric cladding gaincoupled DFB laser with titanium surface gratings by metalorganic chemical vapor deposition," IEEE Photon.

Techno. Lett., 9(4), 422-424 (1997)

13 R. D. Martin, S. Forouhar, S. Keo, R. J. Lang, R. G. Hunsperger, R. C. Tiberio, and P. F. Chapman, "InGaAs-GaAsAlGaAs laterally coupled distributed feedback (LC-DFB) ridge laser diode,"Electron. Lett., 30(13), 1058-1060 (1994)

14 N. Chen, Y. Watanabe, K. Takei, K. Chikuma, "InGaAsP/InP laterally coupled distributed feedback laser," Jpn. J. Appl. Phys. 39(Pt.1) (3B), 1508-1511(2000)

15 Y. Watanabe, N. Chen, K. Takei, K. Chikuma, N. Fudakuchi, and Y. Nakano, "Laterally coupled strained MQW ridge waveguide distributed feedback laser diode fabricated by wet-dry hybrid etching process," IEEE Photon. Techno. Lett., 10(12), 1688-1690 (1998)

16 M. Aoki, T. Tsuchiya, K. Nakahara, M. Komori, K. Uomi, "High-power and wide-temperature-range operations of InGaAsP-InPstrained MQW lasers with reverse-mesa ridge-waveguide structure," IEEE Photon. Techno. Lett. , 7(1), 13-15 (1995)

17 M. Aoki, M. Komori, T. Tsuchiya, H. Sato, K. Nakahara, K. Uomi, "InP- based reversed-mesa ridge-waveguide structure for high-performance long-wavelength laser diodes," IEEE J. of Selected Topics in Quantum Electron., 3(2), 672-683 (1997)

18 B. Xiong, C. Sun, J. Wang, Z. Hao, Y. Luo, "Low threshold DFB laser integrated high speed EA modulators based on ridge waveguide structure by ICP etching," Proc. SPIE, 4905, 161-164 (2002)

19 N. Iwai, T. Mukaihara, N. Yamanaka, K. Kumada, H. Shimizu, and A. Kasukawa, "High-performance 1.3- $\mu \mathrm{m}$

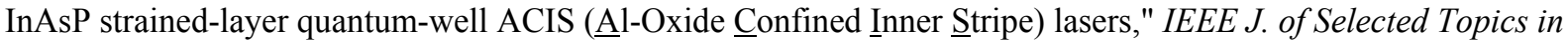
Quantum Electron., 5(3), 694-700 (1999)

20 J. Heerlein, S. Gruber, M. Grabherr, R. Jäger, and P. Unger, "Highly efficient laterally oxidized $\lambda=950 \mathrm{~nm}$ InGaAs-AlGaAs single-mode lasers," IEEE J. of Selected Topics Quantum Electron., 5(3), 701-706 (1999)

21 S. Illek, A. Ultsch, B. Borchert, A. Y. Egorov, H. Riechert,"Low threshold lasing operation of narrow stripe oxideconfined GaInNAs/GaAs multi-quantum well lasers at 1.28 m," Electron. Lett., 36(8), 725-726 (2000)

22 X. Huang A. Stintz, C.P. Hains, G.T. Liu, J. Cheng, K. J. Malloy, "Very low threshold current density room temperature continuous-wave lasing from a single-layer InAs quantum-dot laser," IEEE Photon. Techno. Lett., 12(3), 227-229 (2000)

23 S. Narata, J. Darja, N. Chen, Y. Nakan, "Numerical optimization of ridge waveguide semiconductor lasers with current confinement structure," Digest of the 51th Applied Physics Conference, Tokyo, 31p-ZZ-2 (2004)

24 N. Chen, J. Darja, S. Narata, K. Ikeda, K. Nishide, Y. Nakano, "Ridge semiconductor laser with laterally undercut etched current confinement structure, " IEICE Trans. Electron., E90-C(5), 1105-1110 (2007)

25 U. Koren, T. R. Chen, C. Harder, A. Hasson, K. L. Yu, L. C. Chiu, S. Margalit, and A. Yariv, "InGaAsP/InP undercut mesa laser with planar polyimide passivation, " Appl. Phys. Lett., 42(5), 403-405 (1983)

26 T.R. Chen, P.C. Chen, C. Gee,and N. Bar-Chaim, "A high-speed InGaAsP/InP DFB laser with an air-bridge contact configuration, " IEEE Photon. Techno. Lett., 5(1), 1-3 (1993)

27 T.R. Chen, P.C. Chen, J. Ungar and N. Bar-Chaim, "High Power operation of multi-quantum well DFB lasers at 1.3 $\mu \mathrm{m}$, " Electron. Lett. 31(16), 1344-1345 (1995)

28 T.R. Chen, J. Ungar, X.L. Yeh and N. Bar-Chaim, "Very large bandwidth strained MQW DFB laser

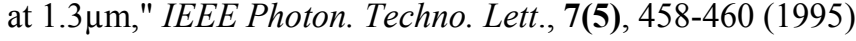

29 K. Uomi, T. Tsuchiya, M. Komori, A. Oka, T. Kawano, A. Oishi, "Ultralow threshold 1.3- $\mu \mathrm{m}$ InGaAsP-InP compressive-strained multiquantum-well monolithic laser array for parallel high-density optical interconnects," IEEE J. of Selected Topics in Quantum Electron., 1(2), 203-210 (1995)

30 T.R. Chen, P.C. Chen, J. Ungar, J. Paslaski,, S. Oh, H. Luong and N. Bar-Chaim, "Wide temperature range linear DFB lasers with very low threshold current, " Electron. Lett., 22(11), 169-170 (1997)

31 T.R. Chen, W. Hsin, and N. Bar-Chain, "Very high power InGaAsP/Inp distributed feedback lasers, " Applied Physics Letter, 72(11), 1269-1271 (1998)

32 N.C. Frateschi, J. Zhang, R. Jambunathan, W.J. Choi, C. Ebert, A.E. Bond, "Uncooled performance of 10-Gb/s 
laser modules with InGaAlAs-InP and InGaAsP-InP MQW electroabsorption Modulators integrated with semiconductor amplifiers" IEEE Photon. Techno. Lett.,, 17(7), 1378-1380 (2005)

T.R. Chen, P.C. Chen, J. Ungar， M.A. Newkirk，S. Oh， N. Bar-Chaim, "Low-threshold and high-temperature operation of InGaAlAs-InP lasers," IEEE Photon. Techno. Lett., 9(1), 17-18 (1997)

K. Nakahara, T. Tsuchiya, T. Kitatani, K. Shinoda, T. Kikawa, F. Hamano, S. Fujisaki, T. Taniguchi, E. Nomoto, M. Sawada, and T. Yuasa, "12.5-Gb/s Direct Modulation Up to $115{ }^{\circ} \mathrm{C}$ in $1.3-\mu \mathrm{m}$ InGaAlAs-MQW RWG DFB lasers with notch-free grating structure, "IEEE/OSA J. of Lightwave Technology, 22(1), 159- (2004)

35 J. Piprek, J. K. White, A.J. SpringThorpe, "What limits the maximum output power of long-wavelength AlGaInAs/InP laser diodes? " IEEE J. of Quantum Electron., 38(9), 1253-1259 (2002)

36 K. Nakahara, K. Kondow, T. Kitatani, Y. Yazawa, K. Uomi, "Continuous-wave operation of long-wavelength GaInNAs/GaAs quantum well laser," Electron. Lett., 32(17), 1585-1586 (1996)

37 M. Kondow, K. Uomi, A. Niwa, T. Kitatani, S. Watahiki and Y. Yazawa, "GaInNAs: A novel material for longwavelength-range laser diodes with excellent high-temperature performance, " Jpn. J. Appl. Phys. 35(Pt.1,2B), $1273-1275$ (1996)

38 T. Kitatani, K. Nakahara, M. Kondow, K. Uomi and T. Tanaka, "A 1.3- $\mu$ m GaInNAs/GaAs single-quantumwell laser diode with a high characteristic temperature over $200 \mathrm{~K}$, " Jpn. J. Appl. Phys. 39(Pt.2, 2A), L86L87 (2000)

39 D. Gollub, S. Moses, M. Fischer, M. Kamp, A. Forchel, " GaInNAs-based distributed feedback laser diodes emitting at 1.5 um," Electron. Lett., 40(7), 427-428 (2004)

40 C. Y. Liu, S. F. Yoon, Z. Z. Sun, and K. C. Yew, "High-temperature operation of self-assembled GaInNAs/GaAsN quantum-dot lasers grown by solid-source molecular-beam epitaxy," Appl. Phys. Lett., 88(2), 081105 (2006)

41 F.H. Peters, M.G. Peters, D.B. Young, J.W. Scott, B.J. Thibeault, S.W. Corzine, L.A. Coldren, "High-power vertical-cavity surface-emitting lasers," Electron. Lett., 29(2), 200-201 (1993)

42 M. Grabherr, R. Jager, M. Miller, C. Thalmaier, J. Herlein, R. Michalzik, K.J. Ebeling, "Bottom-emitting VCSEL's for high-CW optical output power, " IEEE Photon. Techno. Lett., 10(8), 1061-1063 (1998)

43 W. Yuen, G.S. Li, R.F. Nabiev, J. Boucart, P. Kner, R.J. Stone, D. Zhang, M. Beaudoin, T. Zheng, C. He, K. Yu, M. Jansen, D.P. Worland, C.J. Chang-Hasnain, "High-performance $1.6 \mu \mathrm{m}$ single-epitaxy topemitting VCSEL, " Electron. Lett., 36(13), 1121-1123 (2000)

44 J. Boucart, C. Starck, F. Gaborit, A. Plais, N. Bouche, E. Derouin, L. Goldstein, C. Fortin, D. Carpentier, P. Salet, F. Brillouet, J. Jacquet, " 1-mW CW-RT monolithic VCSEL at $1.55 \mu \mathrm{m}$, "IEEE Photon. Techno. Lett., 11(6), 629-631 (1999)

45 A, Fiore, Y.A. Akulova, J. Ko, E. R. Hegblom, L. A. Coldren, "Low-threshold multiple-wavelength verticalcavity laser arrays obtained by postgrowth wet oxidation," Electron. Lett., 34(19), 1857-1858 (1998)

46 S. Nakagawa, E. Hall, G. Almuneau, J. K. Kim, D. A. Buell, H. Kroemer, L. A. Coldren, "1.55- $\mu$ m InP-latticematched VCSELs with AlGaAsSb-AlAsSb DBRs," IEEE J. of Selected Topics in Quantum Electron., 1.7(2), 224-230 (2001)

47 T. Asano, D. Feezell, R. Koda, M.H.M. Reddy, D. A. Buell, A. S. Huntington, E. Hall, S. Nakagawa, L. A. Coldren, "InP-based all-epitaxial 1.3 $\mu \mathrm{m}$ VCSELs with selectively etched AlInAs apertures and Sb-based DBRs," IEEE Photon. Techno. Lett., 15(10), 1333- 1335 (2003)

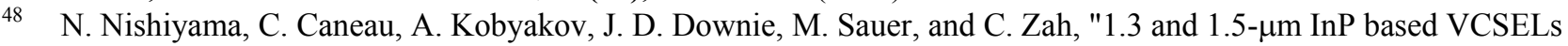
for digital and radio signal transmission," IEEE/OSA Tech. Digest. Of Optical Fiber communication Conference (OFC), OMK4 (2007)

49 A.A. Behfar, and A.J. Morrow, "Etching advance," SPIE's oemagazine, 2, 27-29 (2005)

50 A.A. Behfar, M.G. Green, J. Hwang, A.J. Morrow A.T. Schremer, and C. B. Stagarescu, "Progress in etched facet technology for GaN and blue lasers," CS_MAX, 2005

51 M.L. Osowski, R.M. Lammert, S.W. Oh, D. Qian, and J.E. Ungar, "High power frequency stabilized surface emitting arrays," SSDLTR, poster-12 (2005)

52 N. Kwong, N. Chen, H. Qi, S.B. Chen, J.S. Chen, H. Erlig, T. R. Chen, A. Sherer, "Novel single mode laser using focus ion beam etching," Tech. Digest of 2006 International Optical Fiber Communication Conference (OFC'2006), Anaheim, OWI89 (2006)

53 H. P. Lee, A. Sherer, E.D. Beebe, W.P. Hong, R. Bhat, and M.A. Koza, "1.57 $\mu \mathrm{m}$ InGaAsP/InP surface emitting lasers by angled focus ion beam etching," Electron. Lett., 28(6), 580-582 (1992)

54 K. Uomi, "Uncooled lasers for metropolitan networks," Tech. Digest of the International Semiconductor Laser 
Conference (ISLC), MA1, 1-2 (2006)

55 M-C. Amann, and J. Buus, Tunable laser diodes, Artech House, 1998

56 B. Pezeshki, E. Vail, J. Kubicky, G. Yoffe, S. Zou et. al, "20 mW widely tunable laser module usinf DFB array and MEMS selection," Tech. Digest of Optical Fiber Communication Conference (OFC), 2002

57 L.A. Coldren, "Monolithic tunable diode laser, " IEEE J. of Selected Topics in Quantum Electron., 6(6), 988-999 (2000)

58 H. Ishii, H. Tanobe, F. Kano, Y. Tohmori, Y. Kondo, Y. Yoshikuni, "Quasicontinuous wavelength tuning in super-structure-grating (SSG)DBR lasers, " IEEE J. of Quantum Electron., 32(3), 433-441 (1996)

59 C.J. Chang-Hasnain, "Tunable VCSEL," IEEE J. of Selected Topics in Quantum Electron, 6(6), 978-987 (2000)

60 J. Wesstrom, G. Sarlet, S. Hammerfeldt, L. Lundqvist, P. Szabo, P. Rigole, " State-of-the-art performance of widely tunable modulated grating Y-branch lasers, "Tech. Digest of Optical Fiber Communication Conference (OFC), 2004

61 K. Nakamoto, S. Ide, K. Mori, K. Takabayashi, S. Sekiguchi, A. Hayakawa, H. Kuwatsuka, "High speed wavelength tuning of tunable distributed amplification DFB-LD in long haul transmission," Tech. Digest of Optical Fiber Communication Conference (OFC), JWA31 (2007)

62 Y. Liu, J. Ingham, R. Plumb, R. Penty, I. White, D. Robbins, N. Whitbread, A. Ward, "Directly modulated DS_DBR tunable laser for uncooled C-band WDM system, " Tech. Digest of Optical Fiber Communication Conference (OFC), OThG8 (2006)

63 S. Sudo, K. Mizutani, M. Nielsen, T. Okamoto, K. Tsuruoka, K. Sato, and K. Kudo, "Over $100 \mathrm{~mW}$ out put power operation of VOA integrated full C-band external cavity wavelength tunable laser utilizing high reflective index gap mirror, " Tech. Digest of IEEE International Semiconductor Laser Conference(ISLC), TuB1, 19-20 (2006) N. Chen, A. Kitamoto, Y. Nakano, and K. Tada, "Chirped grating tunable DFB laser - novel laser diode with broader tuning range", Proc. of SPIE, 1979, 347-350 (1993)

65 N. Chen, Y. Nakano, K. Tada, "Fabrication of multiple-electrode chirped-grating-tunable distributed-feedback lasers", Jpn. J. Appl. Phys., 33(Pt.1, 1B), 856-858 (1994)

66 Y. Nakano, Y. Hayashi, N. Chen, Y. Sakaguchi, and K. Tada, "Fabrication and characteristics of an integrated DFB laser/amplifier having reactive-ion-etched tilted end facets", Jpn. J. Appl. Phys., 29, L2430-2433 (1990)

67 M. Takenaka, M. Raburn, and Yoshiaki Nakano, "All-optical flip-flop multimode interference bistable laser diode," IEEE Photon. Techno. Lett., 17(5), 968-970 (2005)

68 M. Sysak, J. Raring, G. Morrison, D. Blumenthal, L. Coldren, "monolithically integrated sampled grating DBR laser transmitter with an asymmetric quantum well electro-absorption modulator, " Tech. Digest of IEEE International Semiconductor Laser Conference (ISLC), TuB6, 29-30 (2006)

69 S. Sumi, K. Naoe, Y. Sakuma, R. Washino, K. Okamoto, K. Motoda, H. Sato, K. Shinoda, T. Kitatani, A. Taike, K. Uomi, "Semi-cooled operation $(\mathrm{TLD}=50 \mathrm{C})$ of $10.7-\mathrm{Gbit} / \mathrm{s} 1.55 \mathrm{~mm}$ electro-absorption modulator integrated DFB laser for $80 \mathrm{~km}$ transmission," Tech. Digest of IEEE International Semiconductor laser conference(ISLC), P23, 85$86(2006)$

70 M. Kwakernaak, W. Chan, N. Maley, H. Mohseni, L. Yang, D. Capewell, B. Kharas, V. Frantz, T. Mood, G Oajer, D. Ackerman, J. Kim, "Multi-frequency laser monolithically integrating InGaAsP gain elements with amorphous silicon AWG, " Tech. Digest of Optical Fiber Communication Conference (OFC), OWH4 (2006)

71 M. Kato, R. Nagarajan, J. pleumeekers, P. Evans, A. Chen, A. Mathur, A. Dentai, S. Hurtt, D. Lambert, P. Chavarkar, M. Missey, J. Back, R. Muthiah, S. Murthy, R. Salvatore, C. Joyner, J. Rossi, R. Schneider, M. Ziari, F. Kish, and D. Welch, "40-channel transmitter and receiver photonics integrated circuit operating at a per channel data rate 12.5 Gbit/s, " Tech. Digest of Optical Fiber Communication Conference (OFC), JThA89 (2007)

72 H. Rong, R. Jones, A. Liu, M. Paniccia, O. Cohen, D. Hak, "Silicon based lasers and amplifiers via stimulated Raman scattering, " Tech. Digest of Optical Fiber Communication Conference (OFC), OWD7 (2006)

73 For example, The Technical White Paper, http://www.xponentinc.com

74 J. E. Bowers, A. W. Fang, H. Park, R. Jones, M. J. Paniccia, O. Cohen, "Hybrid silicon evanescent laser in a siliconon-insulator wave guide," Tech. Digest of Optical Fiber Communication Conference (OFC), OTuK4 (2007)

75 T. Palkert, M. Saberi, "A CMOS photonics based 10 Gbps fiber optic communication link, " Tech. Digest of Optical Fiber Communication Conference (OFC), JThA93 (2007)

76 Y. Itaya, Y. Tohmori, H. Toba, "Spot-size converter integrated laser diodes (SS-LDs)," IEEE J. of Selected Topics in Quantum Electron., 3(3), 968-974 (1997)

77 H. Yamazaki, K. Kudo, T. Sasaki, J. Sasaki, Y. Furushima, Y. Sakata, M. Itoh, M. Yamaguchi, "1.3- $\mu$ m spot-size-converter integrated laser diodes fabricated by narrow-stripe selective MOVPE, " IEEE J. of Selected 
Topics in Quantum Electron, 3(6), 1392-1398 (1998)

78 T. Mizuno, T. Kitoh, M. Itoh, T. Saida, T. Shibata, and Y. Hibino, "Optical spot size converter using narrow laterally tapered waveguide for planar lightwave circuits, " IEEE/OSA J. of Lightwave Techno., 22(3), 833-839 (2004)

79 Y. Kim, Y. Bae, E. Lee, I. Kim, Young Bang, J. Lee, Y. Oh, and D. Jang, "InGaAsP SSC LD for low coast uncooled FTTH module with bandwidth over 4gHz, - manufacturing-ready SSC FP LD for the low cost TRx module for E-PON system," IPRM, 2005

80 Y. Nakano, Y. Deguchi, K. Ikeda, Y. Luo, K. Tada, "Resistance to external optical feedback in a gain coupled semiconductor DFB laser," Tech. Digest of the $12^{\text {th }}$ IEEE International Semiconductor Laser Conference (ISLC), $72-73(1990)$

81 R.T. Sahara, R.A. Salvatore, A. Aohl-Abichedid, and Hanh Lu, "Isolator free transmission at 2.5 Gbits/s over 100 $\mathrm{km}$ of single mode fiber by a $1.55 \mu \mathrm{m} \mathrm{AlGaInAs}$ strained multi-quantum well directly modulated distributed feedback laser diode, " IEEE J. of Quantum Electron., 38(6), 620-625 (2002)

82 H. Su, L. Zhang, A.L. Gray, R. Wang, T.C. Newell. K. J. Malloy, and L.F. Lester, "High external feedback resistance of laterally loss-coupled distributed feedback quantum dot semiconductor lasers, "IEEE Photon. Techno. Lett., 15(11), 1504-1506 (2003)

83 K. Nakamura, S. Miyamura, R. Sekikawa, D. Shimura, S. Nakaya, T. Ori, H. Yaegashi, and Y. Ogawa, "Optical feedback-tolerant $1.3 \mu \mathrm{m}$ gain coupled DFB lasers for isolator-free micro-BOSA modules, " Tech. Digest of Optical Fiber Communication Conference (OFC), OMK5 (2007)

84 H. Shimizau, and Y. Nakano, "First monolithic integration of a waveguide optical isolator with a distributed feedback laser diode, " Tech. Digest of IEEE International Semiconductor Laser Conference(ISLC), TuA6, 17-18 (2006) 